\title{
Modes on the Move: Interval Cycles and the Emergence of Major-Minor Tonality
}

\author{
MATTHEW WOOLHOUSE \\ Centre for Music and Science, Faculty of Music, University of Cambridge, United Kingdom
}

\begin{abstract}
The issue of the emergence of major-minor tonality is addressed by recourse to a novel pitch grouping process, referred to as interval cycle proximity (ICP). An interval cycle is the minimum number of (additive) iterations of an interval that are required for octave-related pitches to be re-stated, a property conjectured to be responsible for tonal attraction. It is hypothesised that the actuation of ICP in cognition, possibly in the latter part of the sixteenth century, led to a hierarchy of tonal attraction which favoured certain pitches over others, ostensibly the tonics of the modern major and minor system. An ICP model is described that calculates the level of tonal attraction between adjacent musical elements. The predictions of the model are shown to be consistent with music-theoretic accounts of common practice period tonality, including Piston's Table of Usual Root Progressions. The development of tonality is illustrated with the historical quotations of commentators from the sixteenth to the eighteenth centuries, and can be characterised as follows. At the beginning of the seventeenth century multiple 'finals' were possible, each associated with a different interval configuration (mode). By the end of the seventeenth century, however, only two interval configurations were in regular use: those pertaining to the modern majorminor key system. The implications of this development are discussed with respect interval cycles and their hypothesised effect within music.
\end{abstract}

Submitted 2010 February 25; accepted 2010 April 26.

KEYWORDS: interval cycles, tonal attraction, major/minor tonality, modality

\section{INTRODUCTION}

THE emergence, both theoretical and concrete, of major-minor tonality in seventeenth-century Europe has long preoccupied scholars with a liking for intractable problems. As Gregory Barnett (2002) points out, in his article on the subject in The Cambridge History of Music Theory, musical thought in the seventeenth century seems awkwardly to fall between, and to be dominated by, the solidity of Renaissance modal theory on the one hand and the stable functional tonal world of the eighteenth century on the other. From our perspective, at least, the musical treatises (and music) of the seventeenth century can sometimes appear to be a peculiar and idiosyncratic blend of modality and tonality, and nor are we alone in finding this troublesome. Also in Gregory Barnett's article is an insightful quotation from the seventeenth-century Italian composer Antonio Maria Abbatini (c. 1609-c. 1679), whose frustration over his then current theoretical predicament was wittily spelled out in a poem to Sig. Bastiano Baldini, c. 1667:

Wherever is that age, so beautiful, When lectures in [the art of] music Were in use (and this is not a tale)?

Thus the science of composing well Was truly lit from every side; [compare] Our own confusion and unhappy state![1] 
In this article I attempt to tackle the thorny issue of major-minor tonality in the seventeenth century by recourse to a grouping model, referred to as interval cycle proximity (Woolhouse, 2007; Woolhouse, 2009; Woolhouse and Cross, 2010). The topic of the emergence of major-minor tonality is as broad as it is controversial. For some the transition to tonality began as far back as the early fifteenth century, whereas for others the year 1700 is an important threshold (Wiering, 2006). Controversy too surrounds that which preceded common practice period tonality. Modality? For sure - but how, for example, did the modes manifest themselves in medieval plainchant? Were they idealised categories, as is the view expressed in Powers and Wiering (2001) (see also Wiering, 2001), or were they in some way a guiding compositional principle. And if the latter was the case, what was the fit between modes and repertoire?

Whatever the answers to these questions, my starting point is that the different aspects of the modal 'system' - final, tenor, ambitus, initial melodic gesture, closing formulae, and so on - can be considered subsets of a melody-dominated, overarching diatonic system. This view, which is necessarily a simplification, is taken from Carl Dahlhaus (1990), who states in his monograph Studies on the Origin of Harmonic Tonality:

The diatonic system is the embodiment of all the modes. And as a result of the modes' mutual effects on polyphonic contexts, it can emerge as the dominant factor, the factor with the primary role in determining the overall musical impression. The modal characters of the Dorian, Phrygian and Ionian species of fifths and fourths do not become completely effaced by their joint encounters within the narrow ambitus of a polyphonic composition. Nevertheless, the constant intertwining and crossing of different melodic modes results in a network of interrelationships that assists the diatonic, the comprehensive system, in achieving precedence over the individual modes. (p. 234).

It would be an understatement to say that empirical/cognitive studies into the historical emergence of tonality are rare; indeed, to date vanishingly little work has been done to trace the important changes in tonal organisation from the sixteenth to eighteenth centuries employing a cognitive approach. This is understandable. Cognitive musicologists are still debating present-day perceptual matters - what chance have we to elucidate those of a bygone musical era, an era that was confusing even for some of its inhabitants, never mind for us who are removed from it by over three-hundred years of musical culture? However, one notable oasis in the research desert that is seventeen-century cognitive musicology is Huron and Veltman's (2006) analysis of the pitch-class distributions in Gregorian chants.[2]

Whilst Huron and Veltman's work is not strictly speaking a study of seventeenth-century music, they did find statistical evidence that they hypothesise might have implications for the emergence of tonality at this time. In brief, Huron and Veltman derived eight tone-frequency "mode profiles" from 98 Gregorian chants, randomly selected from the Liber Usualis (Benedictines of Solesmes, 1961). In their initial analysis they found that in general the profiles could be used to predict the conventional mode designations of a randomly selected group of chants - Dorian, Hypodorian, Phrygian, and so on. Furthermore, Huron and Veltman noticed that some of the mode profiles were similar, and, as a result, in a second analysis they asked whether using Euclidean distance measures supramodal groupings might exist under which two or more modes could be subsumed. Employing a multidimensional scaling technique, a two dimensional solution was found that accounted for nearly all of the pitch class distribution variance. One dimension, in particular, was found to account for the majority of the variance: that which separated all the modes with $\mathrm{C}$ tenors from the others.[3] Huron and Veltman hypothesized that medieval listeners may have had difficulty differentiating modes with shared tenors and similar profiles, "setting the stage for modal merger [...] hundreds of years before Glareanus proposed adding the Ionian and Aeolian modes [in the sixteenth century]" (p. 50).[4]

The work presented here aims to compliment that of Huron and Veltman by proposing a possible cognitive mechanism that may account for the way in which the melodic diatonic system, as envisaged by Dahlhaus, developed into the bi-tonic world of major-minor tonality. The article is in three sections: Section 1 contains a brief description of a model of tonal attraction based on interval cycles, and outlines how it might be actuated in cognition; Section 2 shows how the model is consistent with various musictheoretic and empirical features of common practice period tonality; Section 3 sketches some of the important changes in tonal organisation in the seventeenth century and discusses how the changes may, theoretically at least, be accounted for by the model. 


\section{INTERVAL CYCLE PROXIMITY MODEL}

The word "cycle" implies repetition, and with respect to music the repetition is of pitches whose fundamental frequencies have a $1: 2^{n}$ ratio, where $n$ is an integer greater than 0 . In the equal-tempered system (and other related tuning systems, such as Just Intonation) two pitches separated by a frequency ratio of $1: 2^{n}$ are said to be octave-related, and are usually perceived as equivalent to one another. Considerable empirical evidence exists to justify this assertion (see, for example, Allen, 1967; Thurlow and Erchul, 1977; Lockhead and Byrd, 1981; Demany and Armand, 1984; Dowling and Harwood, 1986), and Wright et al. (2000) found evidence for octave generalization in rhesus monkeys.

An interval cycle is the minimum number of (additive) iterations of an interval that are required for octave-related pitches to be re-stated. For example, if the interval is a major third (four semitones) and the original pitches are $\mathrm{C} 4$ and E4, the first additive iteration of an (ascending) major third states pitch classes E4 and G\#/Ab4, the second additive iteration of a major third states pitch classes G\#/Ab4 and C5, and the third additive iteration of a major third states pitch classes C5 and E5 - the original pitch classes of the cycle. The interval cycle of a major third, therefore, is three. Note that enharmonic intervals are equivalent. That is, the interval cycle of a given interval is calculated with respect to its absolute size in

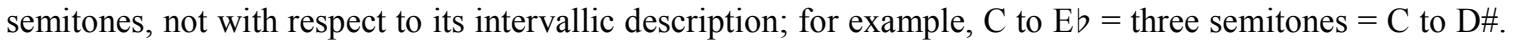
Therefore, unlike interval descriptions such as "major third" or "perfect fourth", which are determined by harmonic context, interval cycles are context-independent.

Interval cycles endow music with an abstract grouping property, which I refer to as interval cycle proximity (henceforth referred to as "ICP"). This property is now briefly explained.[5] Figure 1 shows each interval within an octave iterated additively so that they appear as stacks. Each stack begins at zero on the y-axis (representing the originating note) and continues until it is level with an octave-related pitch (an integer on the y-axis), at which point the interval completes its cycle and the stack terminates. The number of intervals in each stack is the interval cycle of the interval (shown in parentheses on the $\mathrm{x}$-axis). For example, there are six intervals in the major second stack (M2), three intervals in the major third stack (M3), two intervals in the augmented fourth third stack (A4), and so on. Note that some stacks terminate after multiple octaves; for example, the perfect fourth (P4, iterated 12 times) requires five octaves until its originating pitch class is repeated and its stack terminates.

The effect of octave equivalence - in which pitches separated by a frequency ratio of $1: 2^{\mathrm{n}}$ are perceptually highly similar - can be shown by collapsing the multiple octaves on the y-axis in Figure 1, a process which leads to the 'compression' of interval stacks covering more than one octave into a single 'equivalent octave'; see Figure 2.

The effect of collapsing the interval stacks can be seen on the relative sizes of intervals $a$ and $b$ in Figure 2. First, represented by the letter $a$, the minor second and perfect fourth intervals are the same size; second, the minor third, $b$, is larger than the perfect fourth, $a$. This interval-changing effect is not only limited to the minor second, the perfect fourth and the minor third, but is common to all intervals. For example, in the representation in Figure 2 any two pitches a minor third (m3) apart are relatively distant in comparison to any two pitches a perfect fourth (P4) apart; any two pitches a minor seventh apart (m7) are relatively close in comparison to any two pitches an augmented fourth apart (A4), and so on. In the representation in Figure 2, ICP is a result of listeners perceiving octave-related pitches as equivalent and being sensitive to the extent of the subdivision of the equivalent octave by interval cycles. The higher the interval cycle value, i.e., the higher the subdivision, the closer and more strongly grouped two pitches are in the equivalent octave; the lower the interval cycle value, i.e., the lower the subdivision, the more distant and less strongly grouped two pitches are. 


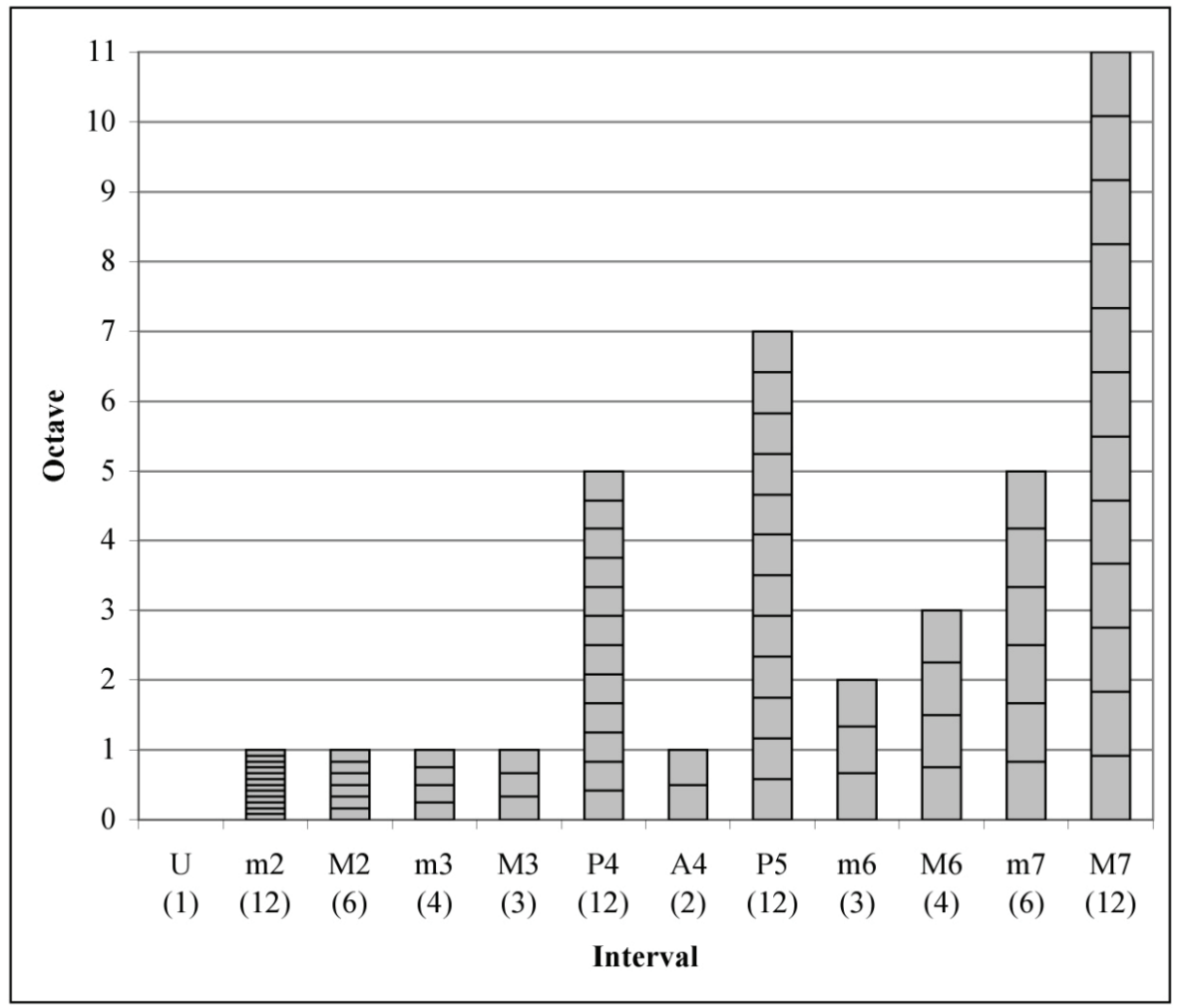

Fig. 1. Graph showing the minimum number of additive iterations of an interval that are required for a pitch bearing the same note-name as the originating pitch (represented by zero on the y-axis) to be repeated. Horizontal lines on the y-axis represent octave-related pitches. Interval cycle values, i.e., numbers of additive iterations, of intervals are shown on the $\mathrm{x}$-axis in parentheses.

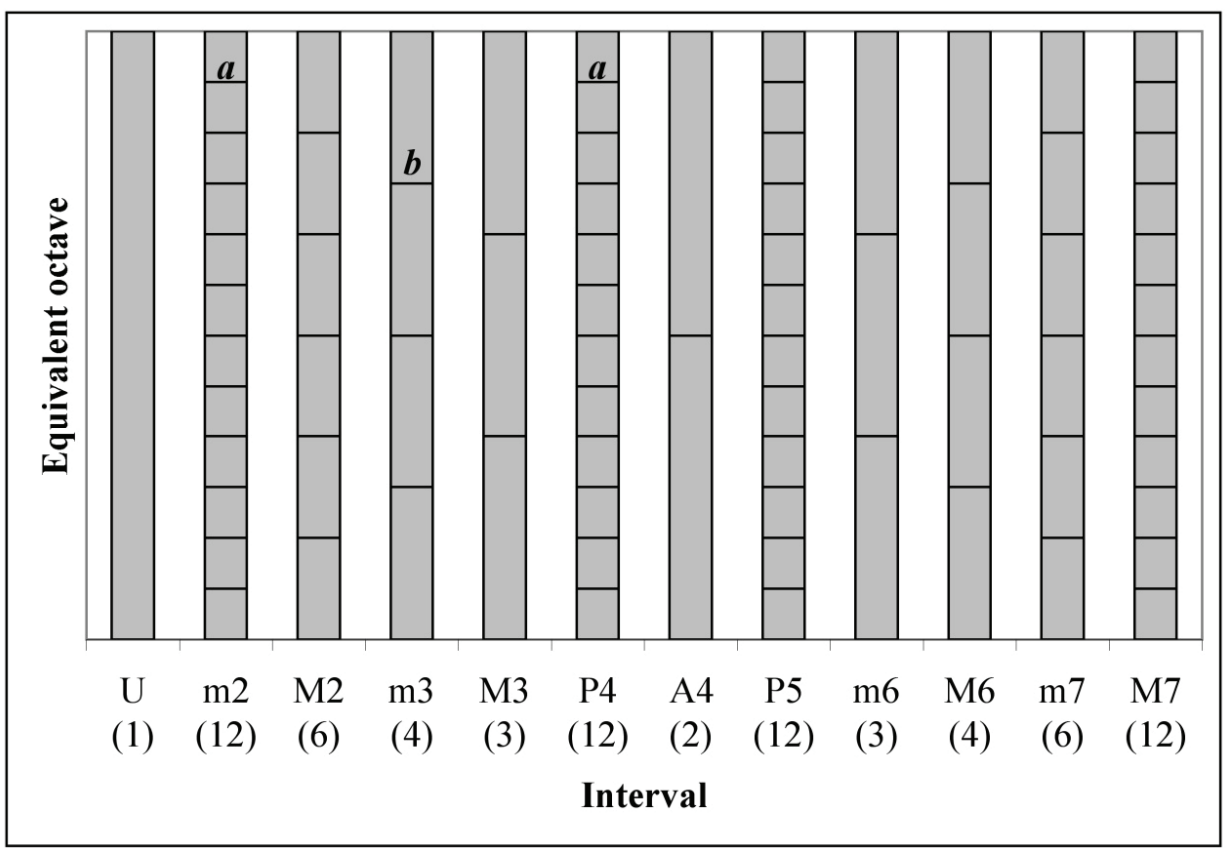

Fig. 2. The equivalent octave in which the interval stacks from Figure 1 are 'compressed' to the same height. 


\section{Interval Cycle Proximity Hypothesis}

The ICP model [6] is based on the following hypothesis (see also Woolhouse, 2007):

Tonal attraction is proportional to the sum of the interval cycles formed between sequential pairs of pitches and/or chords. High interval cycles lead to strong tonal attraction; low interval cycles lead to weak tonal attraction.

The hypothesis is based on the notion that varying degrees of ICP are perceptually integrated with feelings of tonal attraction in the minds of encultured listeners (Woolhouse, 2007). Tonal attraction can be understood as the strength of 'pull' or 'magnetism' between temporally adjacent musical elements, and is related to percepts such as 'stability', 'tensions' and 'resolution'. The higher the interval cycle of two pitches, the closer their proximity in the equivalent octave (Figure 2), which in turn leads to higher tonal attraction; the lower the interval cycle of two pitches, the more distant their proximity in the equivalent octave, which in turn leads to lower tonal attraction. By way of an example, Table 1 shows the interval cycles formed between a $\mathrm{G}^{7}$ chord and the pitches of the $\mathrm{C}$ harmonic minor scale.

\begin{tabular}{|c|c|c|c|c|c|c|c|c|}
\hline & \multicolumn{7}{|c|}{ C harmonic minor scale } \\
\hline & & $\mathrm{C}$ & D & $\mathbf{E} b$ & $\mathbf{F}$ & G & $\mathbf{A} b$ & B \\
\hline \multirow{4}{*}{$\begin{array}{l}G^{7} \\
\text { chord }\end{array}$} & $\mathbf{F}$ & 12 & 4 & 6 & 1 & 6 & 4 & 2 \\
\hline & D & 6 & 1 & 12 & 4 & 12 & 2 & 4 \\
\hline & B & 12 & 4 & 3 & 2 & 3 & 4 & 1 \\
\hline & G & 12 & 12 & 3 & 6 & 1 & 12 & 3 \\
\hline \multicolumn{2}{|l|}{$\Sigma$} & 42 & 21 & 24 & 13 & 22 & 22 & 10 \\
\hline
\end{tabular}

Table 1. Interval cycle formed between a $\mathrm{G}^{7}$ chord and the $\mathrm{C}$ harmonic minor scale. Summed interval cycle vectors (columns) are shown in the summation row at the base of the table (shaded cells).

The values in the bottom row of Table 1 (shaded cells) are the summed interval cycles values of the $\mathrm{G}^{7}$ chord with respect to each pitch of the $\mathrm{C}$ harmonic scale. The bottom row therefore represents the overall interval cycle relationship that each pitch of the $C$ harmonic minor scale has to $\mathrm{G}^{7}$, the dominant seventh in the key of $\mathrm{C}$ minor. The values of the summation row can be plotted to form an "interval cycle profile"; see Figure 3. Furthermore, in light of the hypothesis, the interval cycle profile in Figure 3 can be interpreted as a "tonal attraction profile", in which high summed interval cycle values show pitches for which there is high overall attraction and low summed interval cycle values show pitches for which there is low overall attraction. According to the hypothesis, Figure 3 shows that following a $\mathrm{G}^{7}$ chord there should be a high level of attraction to pitch $\mathrm{C}$ and a low level of attraction to pitch B.[7]

Tonal attraction has been studied in a number of musical contexts, including with respect to tension and prolongation in music. For example, in a study which investigated the cognitive processes involved in listening to a piece of music, Deliège et al. (1996) required listeners to create a coherent piece from bar-length segments of an original piece. Their results indicated that even non-musicians were sensitive to the temporal nature of tonal attraction in that they tended to alternate tension-creating prolongation segments with tension-releasing cadence segments.

Woolhouse (2007), and Woolhouse and Cross (2010) address in detail how ICP might be cognitively linked to tonal attraction. A brief outline of the hypothesized process is as follows. Brower (2000) proposed a cognitive theory of musical meaning based on the idea that (1) cognition is comprised of mapping patterns of thought onto patterns of experience, and that (2) cognition involves the projection of bodily experiences onto patterns in other domains.[8] In Brower's conception, pattern mapping implied that music takes on meaning with respect to itself (and other works within a listener's memorized musical corpus) as a result of a listener's ability to map in-coming musical patterns onto those stored in memory. And cross-domain projections explained how music acquires metaphorical meaning as a result of musical patterns and/or schemas being projected onto the physical experiences that a listener has in relation to their own body. 


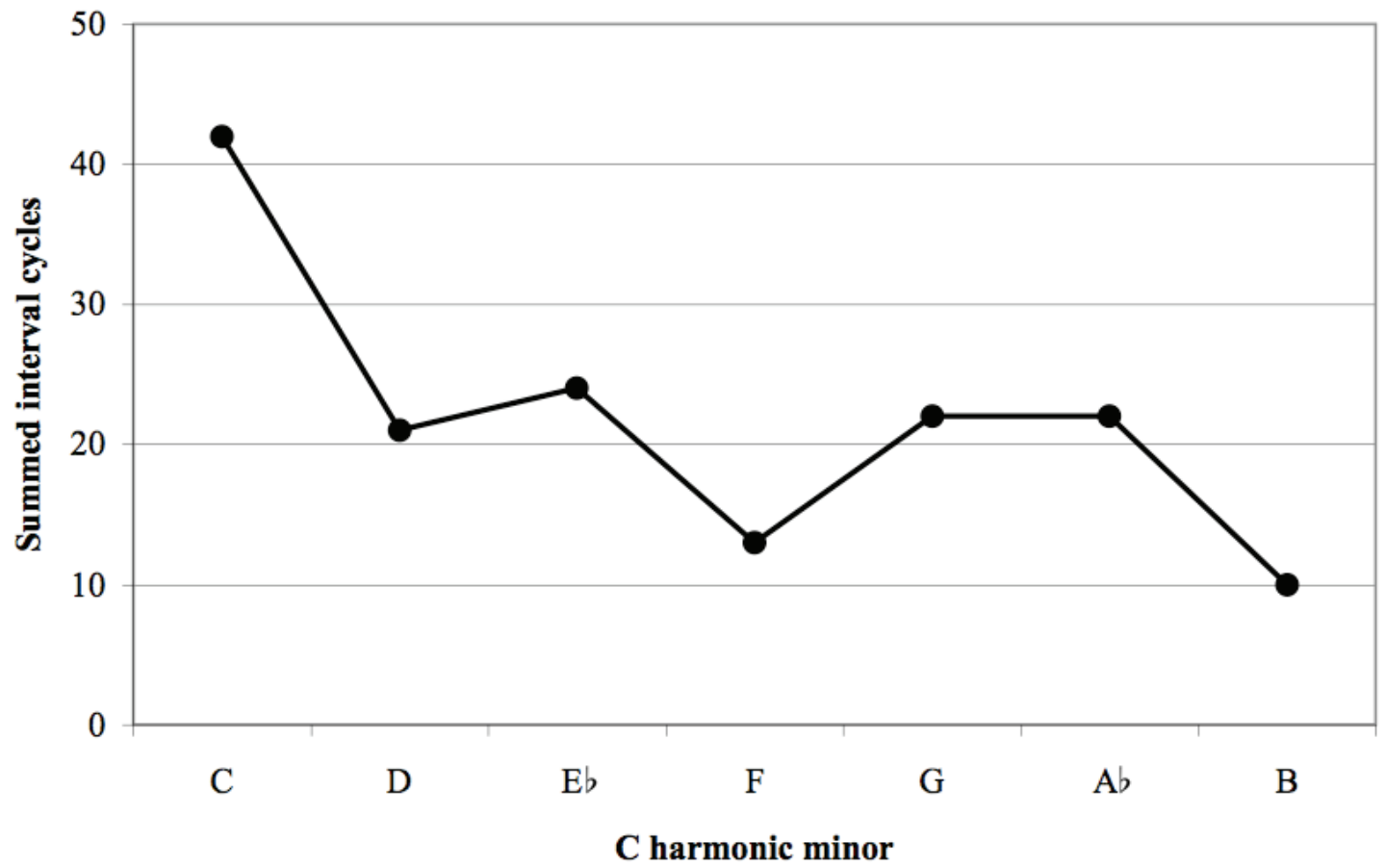

Fig. 3. Interval cycle profile of the $\mathrm{G}^{7}$ chord calculated with respect to each pitch of the $\mathrm{C}$ harmonic minor scale.

As a result of these processes Brower hypothesized that three types of memory-based representations give rise to musical meaning: (1) intra-opus - patterns within a work, such as the recapitulation of the first subject in Sonata Form; (2) musical schemas - abstracted patterns, possibly involving pitch transition probabilities; and (3) image schemas - patterns abstracted from our knowledge of corporeal experiences, force and motion. The crux of Brower's central hypothesis rests on the idea that many aspects of tonal music, including melody, harmony, phrase structure and form, are grounded in image schemas derived from bodily experience. A primary motivation for Brower's work is to uncover the image schemas lying behind tonal music, thereby grounding music with respect to its bodily origins. [9]

In relation to the interval cycle proximity hypothesis, tonal attraction is the result of cross-domain mappings between musical schemas in which ICP is a core structural component and image schemas based on our real-world, physical experiences. This mechanism allows ICP to impart dynamic characteristics onto music that as an inanimate, structural property of the chromatic octave it does not itself possess. ICP is part of the transcriptive information in music onto which are bound different image schemas depending on the specificities of the information, or perhaps a single image schema varying in intensity. As a result, music is able to create different dynamic sensations, many of which are experienced as different degrees of tonal attraction. Finally, it should be noted that image schemas derived from our experience of the physical world must involve certain features such as mass and motion, features that could be said to be synonymous with the experience of tonal music.

\section{INTERVAL CYCLES AND MAJOR-MINOR TONALITY}

The purpose of this section is to show how the ICP model is consistent with a number of aspects of tonality from the common practice period.[10] I begin with some simple observations concerning the relationship between interval cycles and the diatonic and harmonic minor scales, before proceeding to an analysis of chord transitions and Piston's Table of Usual Root Progression (Piston, 1978, p. 21).

The left hand side of Table 2 shows the interval cycles for the pitches of the C-diatonic scale. The sum of each pitch's interval cycle vector (rows) is shown in the table's central summation column. The 
right hand side of Table 2 shows the central summation column's values for the pitches of each diatonic triad. The sum of these values for each triad is shown in the table's bottom right hand summation row.

Of the seven C-diatonic pitch classes on the right hand side of Table 2, C and E have the highest summed interval cycle vectors (shaded rows; $\mathrm{C}$ and $\mathrm{E}$ are both 50). Of the seven possible diatonic triads on the right hand side of Table 2, $\mathrm{C}$ major and $\mathrm{A}$ minor have the highest summed interval cycle vectors (shaded columns; C major and A minor are both 144). Therefore, according to the ICP hypothesis, of the seven possible triads the two with the highest level of attraction are those forming the tonic triads of the major and minor key systems - in this example $\mathrm{C}$ major and A minor.[11]

Even if one is to accept as legitimate the summation process in Table 2, the observations with respect to the tonic triads above may be questioned on a number of grounds. For example, the root of the A minor triad, perceptually the chord's most salient pitch (Parncutt, 1989; Terhardt, 1984), has a lower value than either the third or fifth of the chord $(A=44, C=50, E=50)$. Should not the root have the highest value, i.e., the highest level of attraction? And in addition, when the tonic triad and key is A minor, the leading tone should be G\#, not G-natural as in Table 2. Therefore, although Table 2 may indicate that the $\mathrm{C}$ major triad is important in some way, can the same be said about the A minor triad? In light of these possible objections, it is interesting to observe the interval cycles values of the A-harmonic minor scale that is, when the G-natural of the C-diatonic scale in Table 2 is chromatically raised to a G\#; see Table 3.

\begin{tabular}{|c|c|c|c|c|c|c|c|c|c|c|c|c|c|c|c|}
\hline C diatonic & C & $\mathbf{D}$ & $\mathbf{E}$ & $\mathbf{F}$ & $\mathbf{G}$ & $\mathbf{A}$ & $\mathbf{B}$ & $\sum$ & $\begin{array}{c}\text { C } \\
\text { Major } \\
\text { Triad }\end{array}$ & $\begin{array}{c}\text { D } \\
\text { Minor } \\
\text { Triad }\end{array}$ & $\begin{array}{c}\text { E } \\
\text { Minor } \\
\text { Triad }\end{array}$ & $\begin{array}{c}\text { F } \\
\text { Major } \\
\text { Triad }\end{array}$ & $\begin{array}{c}\text { G } \\
\text { Major }\end{array}$ & $\begin{array}{c}\text { A } \\
\text { Triaor } \\
\text { Triad }\end{array}$ & $\begin{array}{c}\text { B } \\
\text { Dim. } \\
\text { Triad }\end{array}$ \\
\hline B & 12 & 4 & 12 & 2 & 3 & 6 & 1 & 40 & & & 40 & & 40 & & 40 \\
\hline A & 4 & 12 & 12 & 3 & 6 & 1 & 6 & 44 & & 44 & & 44 & & 44 & \\
\hline G & 12 & 12 & 4 & 6 & 1 & 6 & 3 & 44 & 44 & & 44 & & 44 & & \\
\hline F & 12 & 4 & 12 & 1 & 6 & 3 & 2 & 40 & & 40 & & 40 & & & 40 \\
\hline E & 3 & 6 & 1 & 12 & 4 & 12 & 12 & 50 & 50 & & 50 & & & 50 & \\
\hline D & 6 & 1 & 6 & 4 & 12 & 12 & 4 & 45 & & 45 & & & 45 & & 45 \\
\hline C & 1 & 6 & 3 & 12 & 12 & 4 & 12 & 50 & 50 & & & 50 & & 50 & \\
\hline
\end{tabular}

Table 2. Interval cycle matrix for the pitches of the C-diatonic scale. Summed interval cycle vectors are shown in the summation column ( $\sum$, centre). A sum of these values for each diatonic triad (formed by adding the three values in each column) is shown in the summation row ( $\sum$, bottom right).

The left hand side of Table 3 shows the interval cycles for the pitches of the A-harmonic minor scale. The sum of each pitch's interval cycle vector (rows) is shown in the table's central summation column. The right hand side of Table 3 shows the central summation column's values for the pitches of each A-harmonic minor triad. As in Table 2 the sum of these values for each triad is shown in the table's bottom right hand summation row.

Of the seven A-harmonic minor pitch classes on the right hand side of Table 3, A has the highest summed interval cycle vector (shaded row; $A=50$ ). Of the seven possible A-harmonic minor triads on the right hand side of Table 3, A minor has the highest summed interval cycle vector (shaded column; A minor $=140$ ). Therefore, according to the ICP hypothesis, of the seven possible triads the tonic triad has the highest level of attraction - in this example the A minor triad. In addition, the root of the tonic triad now has a higher summed value than the other notes in the chord $(\mathrm{A}=50, \mathrm{C}=41, \mathrm{E}=49)$. A possible consequence of this is that voice leading in a minor key (for example, $\mathrm{G}$ t to $\mathrm{G} \#$ ) comes about in order to promote the hierarchical status of the tonic pitch with respect to interval cycles, and by implication its (hypothesised) level of attraction. 


\begin{tabular}{|c|c|c|c|c|c|c|c|c|c|c|c|c|c|c|c|}
\hline $\begin{array}{c}\text { A } \\
\text { harmonic } \\
\text { minor }\end{array}$ & $\mathbf{A}$ & B & C & D & $\mathbf{E}$ & $\mathbf{F}$ & $\begin{array}{l}\text { G } \\
\#\end{array}$ & $\Sigma$ & $\begin{array}{l}\text { A } \\
\text { Minor } \\
\text { Triad }\end{array}$ & $\begin{array}{c}\text { B } \\
\text { Dim. } \\
\text { Triad }\end{array}$ & $\begin{array}{c}\mathrm{C} \\
\text { Aug. } \\
\text { Triad }\end{array}$ & $\begin{array}{l}\text { D } \\
\text { Minor } \\
\text { Triad }\end{array}$ & $\begin{array}{l}\quad \mathbf{E} \\
\text { Major } \\
\text { Triad }\end{array}$ & $\begin{array}{l}\text { F } \\
\text { Major } \\
\text { Triad }\end{array}$ & $\begin{array}{c}\text { G\# } \\
\text { Dim. } \\
\text { Triad }\end{array}$ \\
\hline G\# & 12 & 4 & 3 & 2 & 3 & 4 & 1 & 29 & & & 29 & & 29 & & 29 \\
\hline $\mathbf{F}$ & 3 & 2 & 12 & 4 & 12 & 1 & 4 & 38 & & 38 & & 38 & & 38 & \\
\hline $\mathbf{E}$ & 12 & 12 & 3 & 6 & 1 & 12 & 3 & 49 & 49 & & 49 & & 49 & & \\
\hline D & 12 & 4 & 6 & 1 & 6 & 4 & 2 & 35 & & 35 & & 35 & & & 35 \\
\hline C & 4 & 12 & 1 & 6 & 3 & 12 & 3 & 41 & 41 & & 41 & & & 41 & \\
\hline B & 6 & 1 & 12 & 4 & 12 & 2 & 4 & 41 & & 41 & & & 41 & & 41 \\
\hline $\mathbf{A}$ & 1 & 6 & 4 & 12 & 12 & 3 & 12 & 50 & 50 & & & 50 & & 50 & \\
\hline & & & & & & & & $\sum$ & 140 & 114 & 119 & 123 & 119 & 129 & 105 \\
\hline
\end{tabular}

Table 3. Interval cycle matrix for the pitches of the A-harmonic minor scale. Summed interval cycle vectors are shown in the summation column $\left(\sum\right.$, centre). A sum of these values for each harmonic minor triad (formed by adding the three values in each column) is shown in the summation row ( $\sum$, bottom right).

Although the forgoing may suggest that there is a link between interval cycles and tonic pitches/chords in tonal music, the method of summing vectors does not reflect music's temporal nature, i.e., that music is built from event transitions. An additional problem, already referred to, is that root salience the phenomenon whereby sensory consonant triads are perceived unitarily, based largely on the functional root of the chord - is not taken into account (each pitch is treated as being equally important). By using the full model as laid out in the Appendix, both these issues are now addressed.

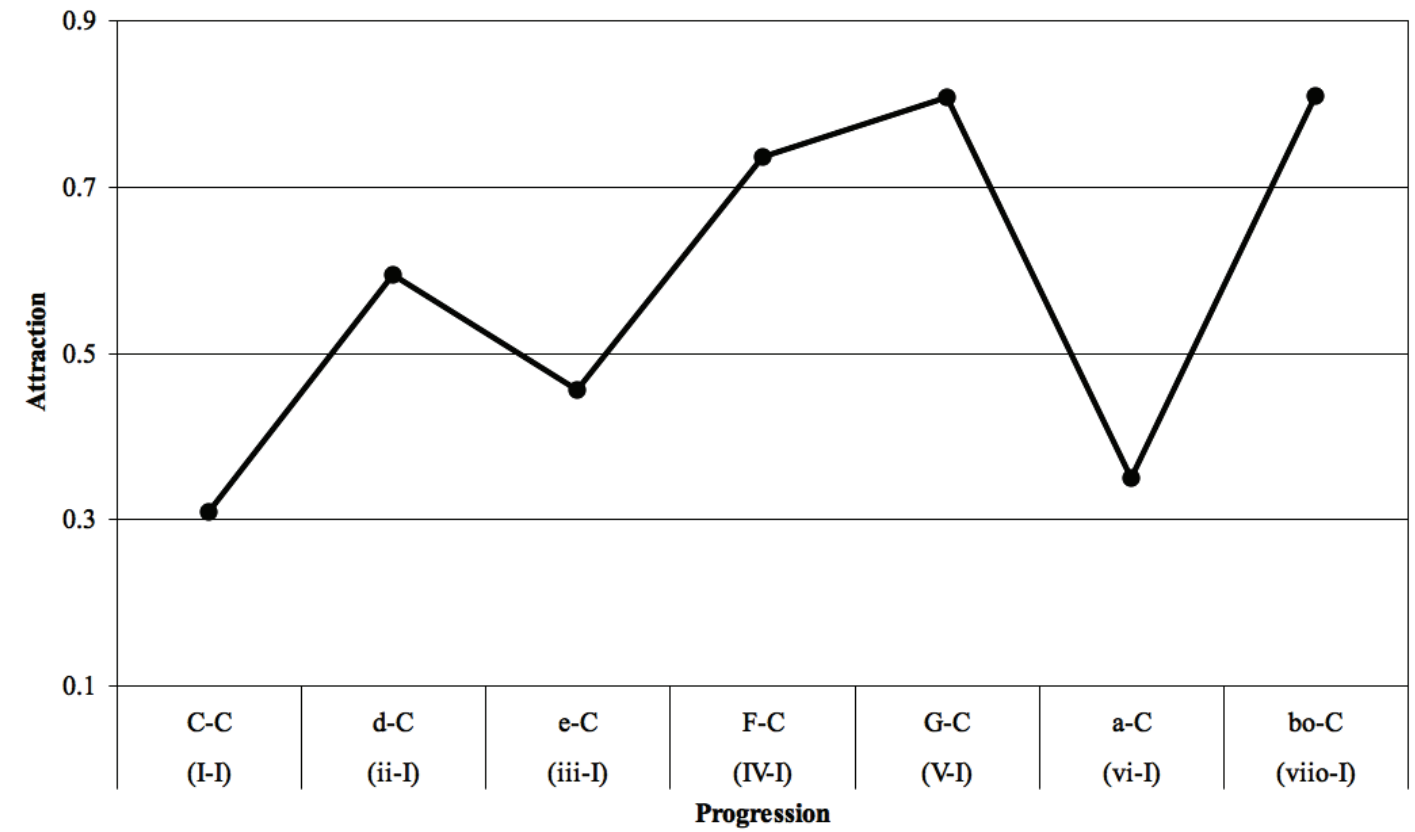

Fig. 4. Chord attraction profile for the seven $\mathrm{C}$-diatonic triads to the $\mathrm{C}$ major triad. The upper labels on the $\mathrm{x}$-axis show the chord names; the lower labels on the $\mathrm{x}$-axis show (in brackets) the functional, musictheoretic descriptions of the progressions.

Figure 4 shows the model's tonal attraction values for the seven triads of C-diatonic $(\mathrm{C}, \mathrm{d}, \mathrm{e}, \mathrm{F}, \mathrm{G}$, $\mathrm{a}, \mathrm{b}^{\circ}$ ) to a $\mathrm{C}$ major triad, displayed as an "attraction profile".[12] In the model-generated attraction profile chords $\mathrm{F}$ major, $\mathrm{G}$ major and $\mathrm{B}$ diminished have relatively high levels of attraction when followed by $\mathrm{C}$ 
major. Of these G-C and $b^{\circ}-\mathrm{C}$ have the highest values, 0.807 and 0.808 respectively. In relation to $\mathrm{C}, \mathrm{G}$ and $\mathrm{b}^{\mathrm{o}}$ together form the dominant seventh, and are therefore members of the most common phrase-ending progression in Western music, the perfect cadence (Piston 1978, p.52). At the end of a phrase in the key of $\mathrm{C}$ major the progression F-C is referred to as a plagal cadence (IV-I, 0.735). None of the remaining chord transitions in Figure 4 form regular cadential progressions. Counter-intuitively perhaps, the attraction of $\mathrm{C}$ to itself $(\mathrm{C}-\mathrm{C})$ has the lowest value (0.308) - should there not be a high level of attraction when a chord is repeated? In order to see why the model's calculation is not inconsistent with the ICP hypothesis, it is necessary to link tonal attraction with musical dynamism: chord transitions with high tonal attraction create a strong sense of dynamic movement; chords with low tonal attraction create a weak sense of dynamic movement. The lack of dynamism or relative stasis created by a chord in relation to itself is therefore compatible with the low level of tonal attraction calculated by the model.

Figure 5 shows the model's attraction profile for the G major triad to the seven triads of Cdiatonic.[13] In the model-generated attraction profile chords $\mathrm{C}$ major, $\mathrm{D}$ minor and $\mathrm{A}$ minor have relatively high levels of attraction when preceded by G major. Of these, G-C (a perfect cadence in the key of $\mathrm{C}$ ) has the highest value (0.807); that is, $\mathrm{G}$ major has the strongest attraction to $\mathrm{C}$ major of the seven possible C-diatonic triads, and therefore according to the model has the strongest tendency to move, or resolve, towards C major perceptually. Although the progression G-d is not a standard cadence, this chord pair could be thought of being a plagal-like progression. The progression G-a is referred to as an interrupted cadence at the end of a phrase. The attraction levels of G-C (0.807) and of G-a (0.606) in Figure 5 model well the relatively strong sense of resolution at a perfect cadence compared to the sense of thwarted resolution at an interrupted cadence.[14]

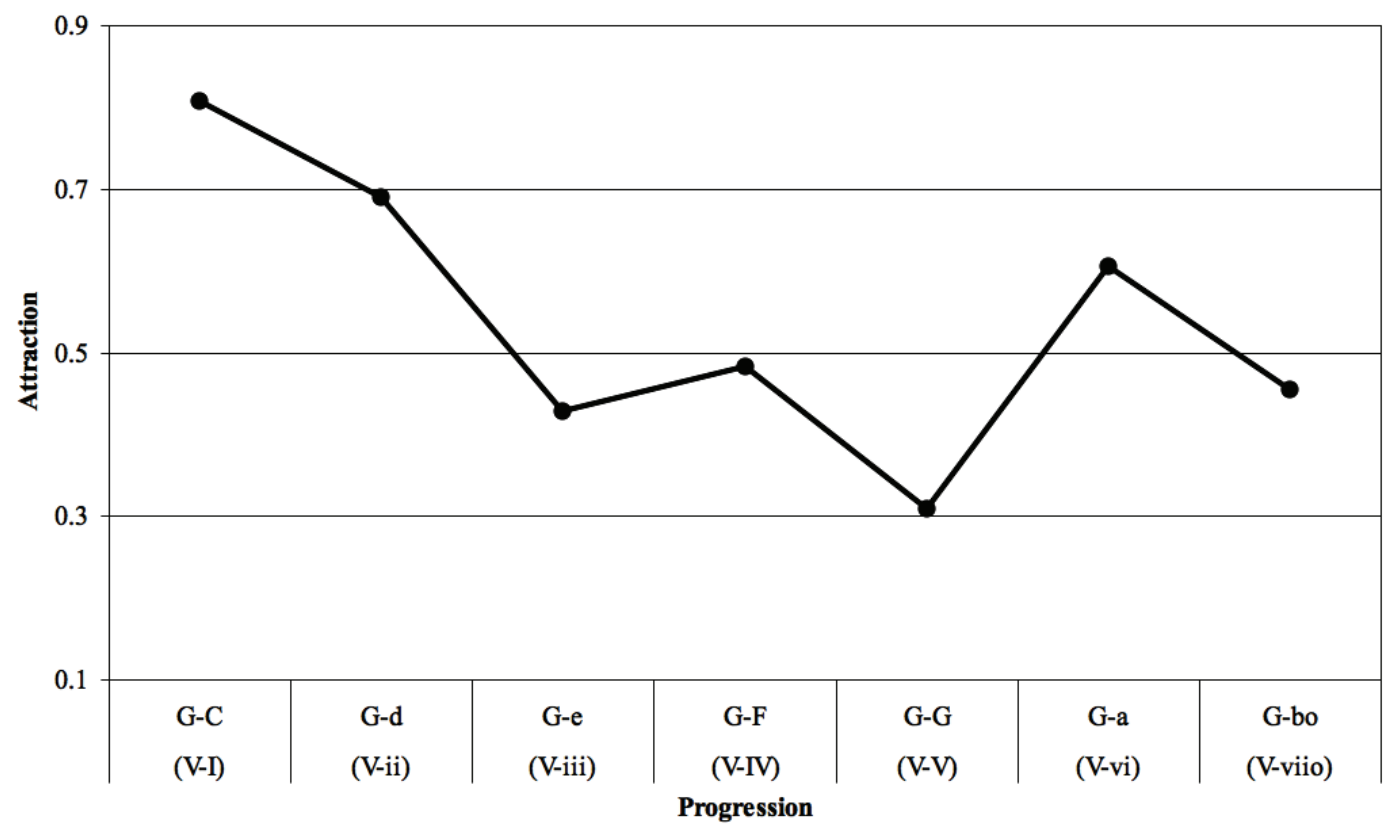

Fig. 5. Chord attraction profile for the G major triad to the seven C-diatonic triads. The upper labels on the $\mathrm{x}$-axis show the chord names; the lower labels on the $\mathrm{x}$-axis show (in brackets) the functional musictheoretic descriptions of the progressions.

An important distinction should be made between the upper and lower (in brackets) x-axis labels in Figures 4 and 5: the upper letter names are root-based descriptions of each C-diatonic triad; the lower Roman numerals are transposable, hierarchical descriptions based on the functional conventions of tonal music. Therefore, while the upper labels carry simply a list of chord names, the lower labels convey information regarding the functional use of triads within the key. One might say that the lower $\mathrm{x}$-axis labels are an emergent property of the upper $\mathrm{x}$-axis labels; that is, given the seven diatonic triads (upper labels), functional attributes (in the form of tonal attractions) emerge within a tonal context that are ascribable to 
diatonic triads (lower labels). Piston's (1978) monograph on harmony contains a 'table of usual root progressions' that allows us to explore the issue of whether the functional organisation of chords within a key might be an emergent property of interval cycles.

\section{Piston's Table of Usual Root Progressions}

Although Piston's table (Piston, 1978, p. 21) is of usual root progressions and not chord progressions, he states "...chord succession can be reduced to root succession (root progression), which in turn can be translated into roman numerals..." (1978, p. 20). In view of this, it is possible to interpret Piston's table as a music-theoretic account of chord transitions, and therefore as being related to music's functional grammar and general chord behaviour.

Piston's table is organised into four columns. The first column (leftmost) lists the seven possible roots or scale degrees (Piston does not specify major or minor mode); the second column lists the roots that often follow each root in the first column; the third column lists the roots that sometimes follow each root in the first column; and the fourth column lists the roots that seldom follow each root in the first column.

Table 4 shows Piston's table and the model's tonal attraction values for each chord pair built on the transitions specified by Piston. For example, in the top left of the table Piston specifies that IV often follows I, beneath which is the model's tonal attraction value for the progression I-IV (e.g., C major triad to F major triad, 0.807). Also added to Table 4 on the right is the list of roots/chords not considered by Piston (and their respective tonal attraction values).[15] If a strong level of attraction between two triads leads to a high probability of their sequential occurrence in music, then it can be hypothesised that in general strongly attracted chord pairs should aggregate to the left of Piston's table (often follows or sometimes follows), and weakly attracted chord pairs should aggregate to the right (seldom follows or not considered).

\begin{tabular}{|c|c|c|c|c|c|c|c|c|c|c|c|}
\hline \multicolumn{2}{|c|}{ Root / Chord } & \multicolumn{2}{|c|}{$\begin{array}{l}\text { Often } \\
\text { follows }\end{array}$} & \multicolumn{2}{|c|}{$\begin{array}{l}\text { Sometimes } \\
\text { follows }\end{array}$} & \multicolumn{3}{|c|}{$\begin{array}{l}\text { Seldom } \\
\text { follows }\end{array}$} & \multicolumn{3}{|c|}{$\begin{array}{l}\text { Not } \\
\text { Considered }\end{array}$} \\
\hline I & $\begin{array}{l}\text { Piston } \\
\text { Model }\end{array}$ & $\begin{array}{l}\text { IV } \\
0.807\end{array}$ & $\begin{array}{l}\mathrm{V} \\
0.735\end{array}$ & $\begin{array}{l}\text { vi } \\
0.428\end{array}$ & & $\begin{array}{l}\text { ii } \\
0.606\end{array}$ & $\begin{array}{l}\text { iii } \\
0.303\end{array}$ & & $\begin{array}{l}\mathrm{I} \\
0.308\end{array}$ & $\begin{array}{l}\mathrm{vii}^{\circ} \\
0.396\end{array}$ & \\
\hline ii & $\begin{array}{l}\text { Piston } \\
\text { Model }\end{array}$ & $\begin{array}{l}\mathrm{V} \\
0.728\end{array}$ & & $\begin{array}{l}\text { IV } \\
0.350\end{array}$ & $\begin{array}{l}\text { vi } \\
0.700\end{array}$ & $\begin{array}{l}\text { I } \\
0.594\end{array}$ & $\begin{array}{l}\text { iii } \\
0.650\end{array}$ & & $\begin{array}{l}\text { ii } \\
0.322\end{array}$ & $\begin{array}{l}\text { vii }^{\circ} \\
0.148\end{array}$ & \\
\hline iii & $\begin{array}{l}\text { Piston } \\
\text { Model }\end{array}$ & $\begin{array}{l}\text { vi } \\
0.744\end{array}$ & & $\begin{array}{l}\text { IV } \\
0.756\end{array}$ & & $\begin{array}{l}\mathrm{I} \\
0.456\end{array}$ & $\begin{array}{l}\mathrm{ii} \\
0.606\end{array}$ & $\begin{array}{l}\mathrm{V} \\
0.350\end{array}$ & $\begin{array}{l}\text { iii } \\
0.322\end{array}$ & $\begin{array}{l}\text { vii }^{\circ} \\
0.343\end{array}$ & \\
\hline IV & $\begin{array}{l}\text { Piston } \\
\text { Model }\end{array}$ & $\begin{array}{l}\mathrm{V} \\
0.550\end{array}$ & & $\begin{array}{l}\mathrm{I} \\
0.735\end{array}$ & $\begin{array}{l}\text { ii } \\
0.428\end{array}$ & $\begin{array}{l}\text { iii } \\
0.794\end{array}$ & $\begin{array}{l}\text { vi } \\
0.35\end{array}$ & & $\begin{array}{l}\text { IV } \\
0.308\end{array}$ & $\begin{array}{l}\text { vii }^{\circ} \\
0.183\end{array}$ & \\
\hline $\mathbf{V}$ & $\begin{array}{l}\text { Piston } \\
\text { Model }\end{array}$ & $\begin{array}{l}\mathrm{I} \\
0.807\end{array}$ & & $\begin{array}{l}\text { IV } \\
0.483\end{array}$ & $\begin{array}{l}\mathrm{vi} \\
0.606\end{array}$ & $\begin{array}{l}\text { ii } \\
0.689\end{array}$ & $\begin{array}{l}\text { iii } \\
0.428\end{array}$ & & $\begin{array}{l}\mathrm{V} \\
0.308\end{array}$ & $\begin{array}{l}\text { vii }^{\circ} \\
0.231\end{array}$ & \\
\hline vi & $\begin{array}{l}\text { Piston } \\
\text { Model }\end{array}$ & $\begin{array}{l}\text { ii } \\
0.744\end{array}$ & $\begin{array}{l}\mathrm{V} \\
0.594\end{array}$ & $\begin{array}{l}\text { iii } \\
0.700\end{array}$ & $\begin{array}{l}\text { IV } \\
0.456\end{array}$ & $\begin{array}{l}\text { I } \\
0.350\end{array}$ & & & $\begin{array}{l}\text { vi } \\
0.322\end{array}$ & $\begin{array}{l}\text { vii }^{\circ} \\
0.333\end{array}$ & \\
\hline vii $^{\mathbf{O}}$ & $\begin{array}{l}\text { Piston } \\
\text { Model }\end{array}$ & $\begin{array}{l}\text { iii } \\
1.117\end{array}$ & & $\begin{array}{l}\mathrm{I} \\
1.214\end{array}$ & & & & & $\begin{array}{l}\text { ii } \\
0.417\end{array}$ & $\begin{array}{l}\text { IV } \\
0.446\end{array}$ & $\begin{array}{l}\mathrm{V} \\
0.767\end{array}$ \\
\hline & & & & & & & & & $\begin{array}{l}\text { vi } \\
0.950\end{array}$ & $\begin{array}{l}\text { vii }^{\circ} \\
0.213\end{array}$ & \\
\hline
\end{tabular}

Table 4. Piston's (1978) table of usual root progressions. Also included are the model's tonal attraction values for each chord pair. In the model the weighting of the past chords' roots $(\beta)$ was 4 ; the weighting of the present chords' roots $(\gamma)$ was 8 ; the variable controlling the influence of the dissonance of chord vii ${ }^{\circ}, \delta$, was 0.5. See Appendix for an explanation of $\beta, \gamma$ and $\delta$.

The level of agreement between the model's forty-nine chord pair attraction values (seven triads $\times$ seven triads) and Piston's four usual root progression categories was determined by giving a value of 4 to column Often Follows, 3 to column Sometimes Follows, 2 to column Seldom Follows and 1 to column 
Not Considered, and by calculating the Spearman rank correlation coefficient $\left(r_{\mathrm{s}}\right)$ between the two data sets: $r_{\mathrm{s}}(47)=0.657 ; p<0.005$.[16] The mean tonal attraction values of chord pairs belonging to Piston's four categories calculated by the model were: Often Follows, 0.759; Sometimes Follows, 0.623; Seldom Follows, 0.515; and Not Considered, 0.372.

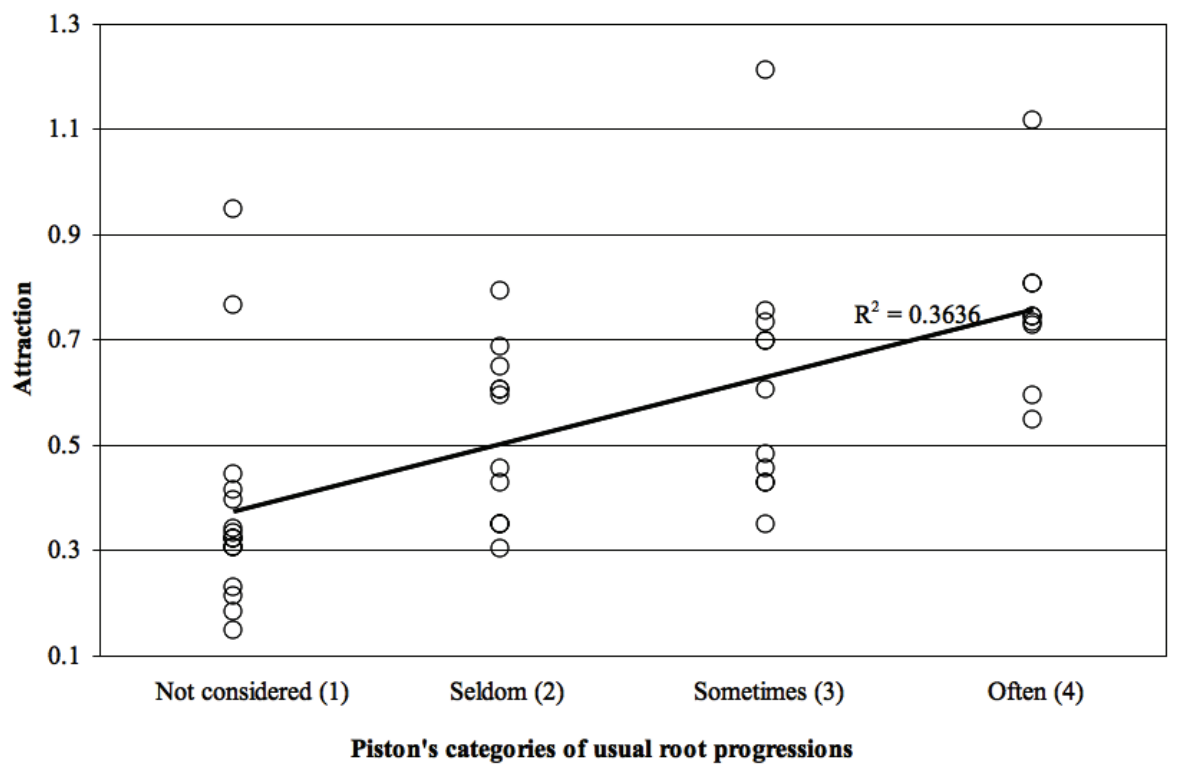

Fig. 6. Scatter-plot of Piston's four categories of usual root progressions against the 49 chord pair attraction values in Table 2.

Figure 6 shows the relationship between the model's tonal attraction values and Piston's four usual root progression categories as a scatter-plot. The correlation coefficient $r_{\mathrm{s}}=0.657$ for $\mathrm{n}=49$ indicates that there is broad agreement between Piston's table and the model's tonal attraction values. This correspondence continues to be significant when the implied Not Considered category is removed from the calculation $\left(r_{\mathrm{s}}(30)=0.515 ; p<0.005\right)$. From these results it appears that chord pairs with higher levels of attraction within the model are more likely to occur (Often Follows) than chord pairs with lower levels of attraction (Seldom Follows), and thus it could be argued that ICP might have been associated with the formation of chord transition probabilities.

Despite the results of the preceding analysis, doubts can be raised due to the subjective nature of Piston's table. The chord transitions are based on Piston's working knowledge of harmony which, although obviously considerable, is subjective rather than objective. Despite this caveat empirical evidence has been found that supports Piston's observations, the data of which are relevant to the present study.

Schmuckler (1989) tested the accuracy of Piston's table in a set of experiments that examined listeners' and performers' expectations of melody and harmony. Schmuckler's second experiment (Harmonic Expectancies, pp. 128-135) presented musically trained listeners with the first eight bars of the piano accompaniment to Robert Schumann's "Du Ring an meinem Finger" from the song cycle Frauenliebe und Leben (Op. 42). At ten positions within the context the music was stopped and one of seven possible diatonic probe chords was provided as a continuation. Transition to the probe was made as smooth as possible by matching the temporal and textural features of the probe with those of the preceding context. Listeners rated on a seven-point scale how well the probe chord fitted their expectations of what was to come next.

The hypothesis underpinning Schmuckler's experiment was similar to that motivating the correlation analysis presented above: if Piston's table is indicative of listeners' harmonic expectancies, then given the particular context chord (i.e., the last chord before the probe), chords that Piston categorised as Often Follows should receive higher ratings than chords categorised as Sometimes Follows. Similarly, given the particular context chord, probes categorised as Sometimes Follows should receive higher ratings than chords categorised as Seldom Follows, and so on. 


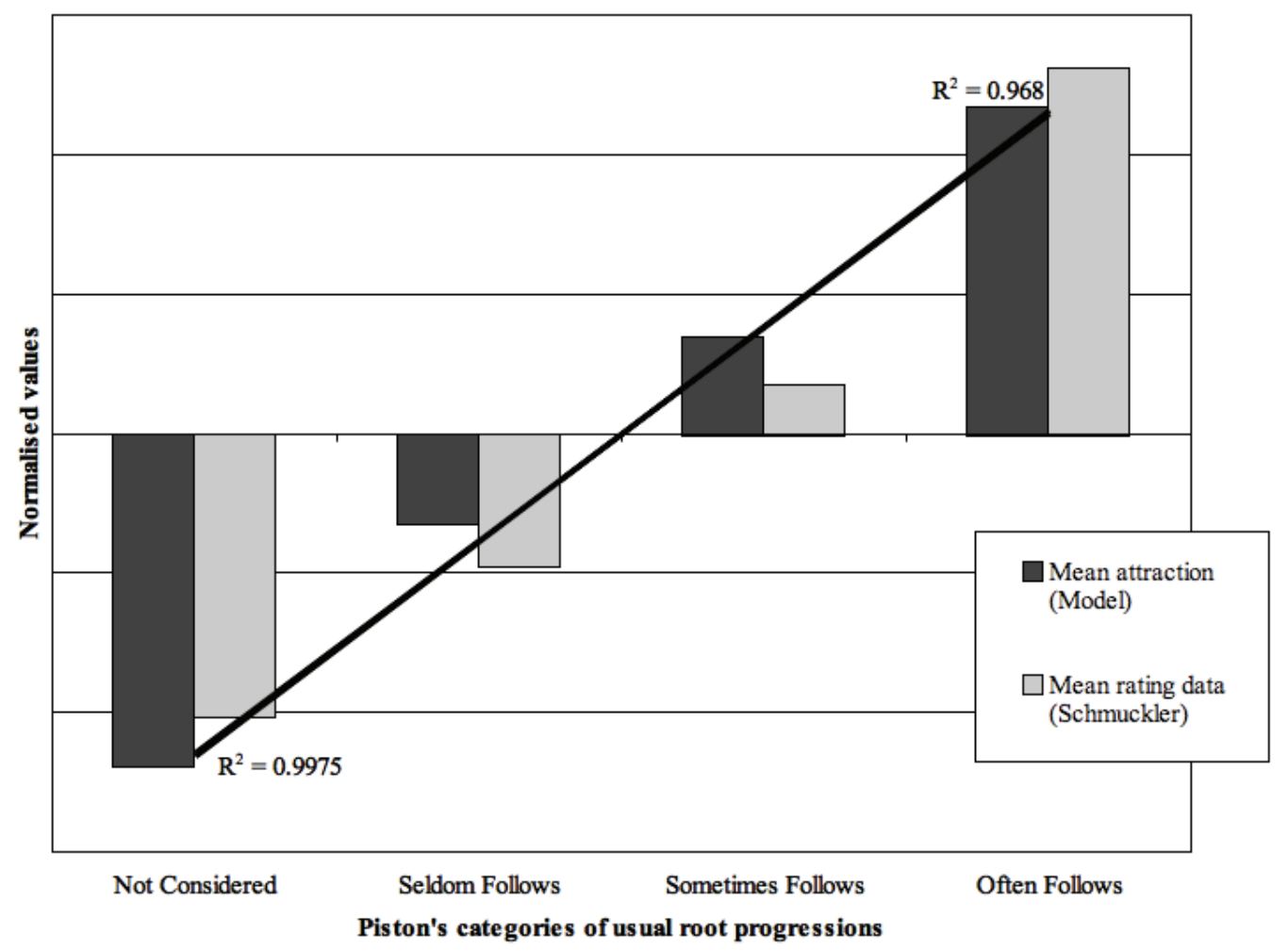

Fig. 7. Bar chart showing the mean tonal attraction values (model) and mean ratings (Schmuckler) for each of Piston's four usual root progression categories: often follows, sometimes follows, seldom follows and not considered. The model and Schmuckler mean values have been normalised. The bottom R-square value (0.9975) refers to the mean chord attraction data (model); the R-square value (0.968) at the top of the figure refers to the mean rating data (Schmuckler).

Across the ten probe positions used by Schmuckler the average rating of chords belonging to Piston's four categories were: Often Follows, 4.92; Sometimes Follows, 4.25; Seldom Follows, 3.87; and Not Considered, 3.55. An ANOVA ascertained that these data differed significantly. Unfortunately, the absence of the mean rating data for individual probes in Schmuckler's (1989) paper makes it impossible to carry out a detailed comparison with the chord attraction values in Table 2. However, despite $n$ being low (only 4), an analysis of the two sets of means (Schmuckler's and the model's) for each of Piston's four categories showed that there was a significant correlation between the ratings data recovered by Schmuckler and the chord attraction data: $r(2)=0.983 ; p<0.05$. Figure 7 shows the similarity of the normalised means of Schmuckler's ratings data and chord attraction data across Piston's four categories. The linear trend lines for the two sets of data are so similar as to appear as a single line.

This section has shown that the ICP model is consistent with a number of tonal features from the common practice period. Most notably, the tonic triads of the diatonic and harmonic minor scales are 'privileged' with respect to interval cycles, which, according the ICP hypothesis may indicate that the major-minor tonics have a greater degree of attraction than non-tonics. The attraction profiles of C-diatonic chord transitions suggested that chord function within tonal music could be in part an emergent property of interval cycles. And the correlation analysis between Piston's four categories of usual root progressions and tonal attraction values, and listeners' ratings of chord expectation based on Piston's four categories and tonal attraction values supports the view that Piston's frequency of chord pair occurrence and Schmuckler's chord expectation data may also be linked to tonal attraction mediated by ICP. These findings are now discussed from a historical, developmental perspective. 


\section{INTERVAL CYCLES AND THE HISTORICAL DEVELOPMENT OF TONALITY}

To propose that the development of Western tonal music may be linked to, or perhaps even the result of an underlying (hypothesised) cognitive process such as ICP might appear unduly deterministic, even positivistic, and, for example, the antithesis of the historiography advanced by Susan McClary, for whom music is "a medium that participates in social formation by influencing the ways we perceive our feelings, our bodies, our desires, our very subjectivities" (McClary, 1994). The following ideas, however, are not intended as an explanation of music's social role and meaning; rather, they are an attempt to provide an account of music's broad structural development from the sixteenth to eighteenth centuries. The dimension of cultural meaning, and the way in which this meaning may have interacted with and shaped music is well beyond the scope of this article.

The following quotations from musical treatises from the sixteenth to the eighteenth centuries trace an important conceptual and perceptual change underlying the development of music at this time, namely the emergence of the modern major and minor key system.[17]

It is evident from the previous discussion that the entire difference between the modes arises from the changing of the fifth and the fourth within the octave in which all the modes fit. But this variation arises from the different placing of the semitone, which alters the entire situation. It is also evident that the Lydian and Hypolydian modes have a common fifth, namely, the third species; the Phrygian and Hypophrygian have a common fifth, the second species, each of which includes the tritone, a hard interval, and somewhat unsuitable to the diatonic system...

\section{Glarean (1547), Dodecachordon}

Ionian, with its secondary Hypoionian, having the triad c-e-g (bo, di, lo), is the most natural and primary of all in today's music (many past and present writers do not agree with this).

Lippius (1612), Synopsis musicae novae

Today's music is entirely different... and only some four modes are in use: Ionian, mixed with Mixolydian and Dorian mixed with Aeolian, mostly in the range of the fourth [that is, these modes differ only in the placement of the semitone in the upper fourth of the mode]. Thus no more than two modes can now be established. And this is not so unnatural if we use them in the correct order.

Werkmeister (1687), Musicae mathematicae

There are twice as many modes as there are notes in each octave: each of these notes gives its name to two modes, of which one proceeds by the major third and the other by the minor. Since the octave contains twelve notes, there are twenty-four modes.

Ozanam (1691), Dictionaire mathématique

According to the present division of the keyboard we have no more than twelve different tones, which are the twelve semitones of the chromatic octave, each of which can be changed once by the minor or major third; thus the twenty-four above mentioned keys arise and remain just twenty-four.

$$
\text { Mattheson (1713), Das neu-eröffnete Orchestre }
$$

The conceptual change from Glarean to Werkmeister, via Lippius, can be characterised as follows: the modal system, which was primarily melodic in conception and which permitted six of the seven diatonic tones to act as 'finals' (i.e., putative tonics [18]), gradually coalesced into the tonal-harmonic system in which only two types of final were recognised - those with a major or minor third above the final (see also Dahlhaus, 1990, pp. 243-47). By the late seventeenth century the French mathematician Ozanam observed that the pattern of semitones and tones above the two principal finals was (more or less) fixed and, given the semitone division of the octave, when exhaustively transposed yielded twenty-four modes. Mattheson articulated this idea in terms of major and minor keys early in the eighteenth century. This development is 
summarised by Chafe (1992, pp. 22-23) who states, "[a]t the beginning of the seventeenth century there were only two key signatures in common use, each with a variety of modes subsumed beneath it. At the end practically all our modern signatures were available; the number of modes within each signature, however, had dropped precipitously, often to no more than two, our major and minor".

Chafe's developmental summary can be expressed in terms of interval configurations and finals, or 'tonal centres'. At the beginning of the seventeenth century multiple finals were possible, each associated with a different interval configuration. For example, the ascending stepwise interval configuration of the Ionian mode was $\underline{\mathbf{T}}, \mathrm{T}, \mathrm{S}, \mathrm{T}, \mathrm{T}, \mathrm{T}, \mathrm{S}$ (the final is indicated in bold and underlined; $\mathrm{T}$ stands for 'tone', $\mathrm{S}$ for 'semitone'), the interval configuration of the Dorian mode was $\mathbf{T}, \mathrm{S}, \mathrm{T}, \mathrm{T}, \mathrm{T}, \mathrm{S}, \mathrm{T}$, and the interval configuration of the Phrygian mode was $\underline{\mathbf{S}}, \mathrm{T}, \mathrm{T}, \mathrm{T}, \mathrm{S}, \mathrm{T}, \mathrm{T}$, and so on. By the end of the seventeenth century, however, only two interval configurations were in regular use: $\underline{\mathbf{T}}, \mathrm{T}, \mathrm{S}, \mathrm{T}, \mathrm{T}, \mathrm{T}, \mathrm{S}$ (the configuration of the modern major key), and $\underline{\mathbf{T}}, \mathrm{S}, \mathrm{T}, \mathrm{T}, \mathrm{S}, \mathrm{T}, \mathrm{T}$ (the configuration of the modern minor key).[19]

I would like to propose that the reason why the diatonic system (as envisaged by Dahlhaus, 1990) coalesced around one or two pitches may have been due to perceptual processes involving tonal attraction. At this point we should perhaps ask the following: what is it that is perceptually special about the tonic? Meyer (1956) and Krumhansl (1990) view the tonic as being more stable than other pitches - but as Krumhansl points out, stability also has dynamic implications: unstable pitches tend to resolve and move to stable pitches.[20] Larson (2004) views the tonic as having unique gravitational and magnetic qualities; that is, there is a strong tendency for pitches to move down (gravity), or up and down (magnetism) towards the tonic. And Bharucha's (1996) characterisation of the dynamism of musical tones is in terms of "tonal force vectors" and "melodic anchoring" whose influences are usually greatest with respect to the tonic.

Let us suppose that during the seventeenth century the actuation of ICP in cognition gradually strengthened. How would this have affected the diatonic modal system? One possible answer can be found in the interval cycle matrices of the C-diatonic scale and A-harmonic minor scale presented in Tables 2 and 3. To recapitulate briefly, the right-hand side of Table 2 showed that of the seven possible C-diatonic triads, $\mathrm{C}$ major and A minor had the highest summed interval cycle vectors. That is, according to the ICP hypothesis, the two triads with the highest level of attraction are those forming the tonic triads of the major and minor key system, C major and A minor in Table 2. With respect to the A-harmonic minor scale, the right hand side of Table 3 showed that of the seven possible triads, the A minor triad has the highest summed interval cycle vector.

A supposition that can be drawn from this is that prior to the seventeenth century ICP did not determine the level of tonal attraction between pitches, and thus that virtually any pitch from the diatonic system could form the final of a modal composition. When, however, during the seventeenth century ICP became a cognitive mechanism influencing tonal attraction, some finals, due to their intervallic configuration, created a stronger sense of attraction (or "gravity" and "stability") than others. According to the ICP hypothesis, the triads on the right-hand side of Table 2 and 3 with the highest summed vectors, should have emerged as those best suited to form the terminal chords of a piece of music. And, as already stated, the two chords that have this property turn out to be the tonic triads of the modern major and minor key system.

Clearly, this hypothesis is speculative, and I am not proposing that interval cycles are sufficient in themselves to explain the complex and convoluted development that took Western music from mode to key in the seventeenth century. For example, the values in Tables 2 and 3 do not take account of the perceptual importance of the roots of chords. Nor do Tables 2 and 3 tell us anything about the transitional relationships between triads. It is interesting to note, however, that when the tonal attraction between diatonic chord pairs is calculated taking into account the perceptual salience of the roots (as in Figures 4 and 5), profiles are generated that are consistent with theoretical accounts of functional tonality. For this reason, despite the degree of speculation involved, I wish to propose that in addition to contributing to the hierarchical significance of the major and minor tonic triads, ICP may also be partially responsible for some of the important transitional relationships in tonal music, most notably that between the dominant and tonic triads. The high level of attraction between these elements in Figures 4 and 5, and the finding that Piston's Table of Usual Root Progressions can be loosely modelled using ICP arguably support this conjecture.

Figure 8 is a schematic diagram of the hypothesised role played by ICP in the development of Western tonal music from the late sixteenth century to the early eighteenth century. The increasing influence of ICP in cognition is represented by the widening grey band running from left to right in the figure. 


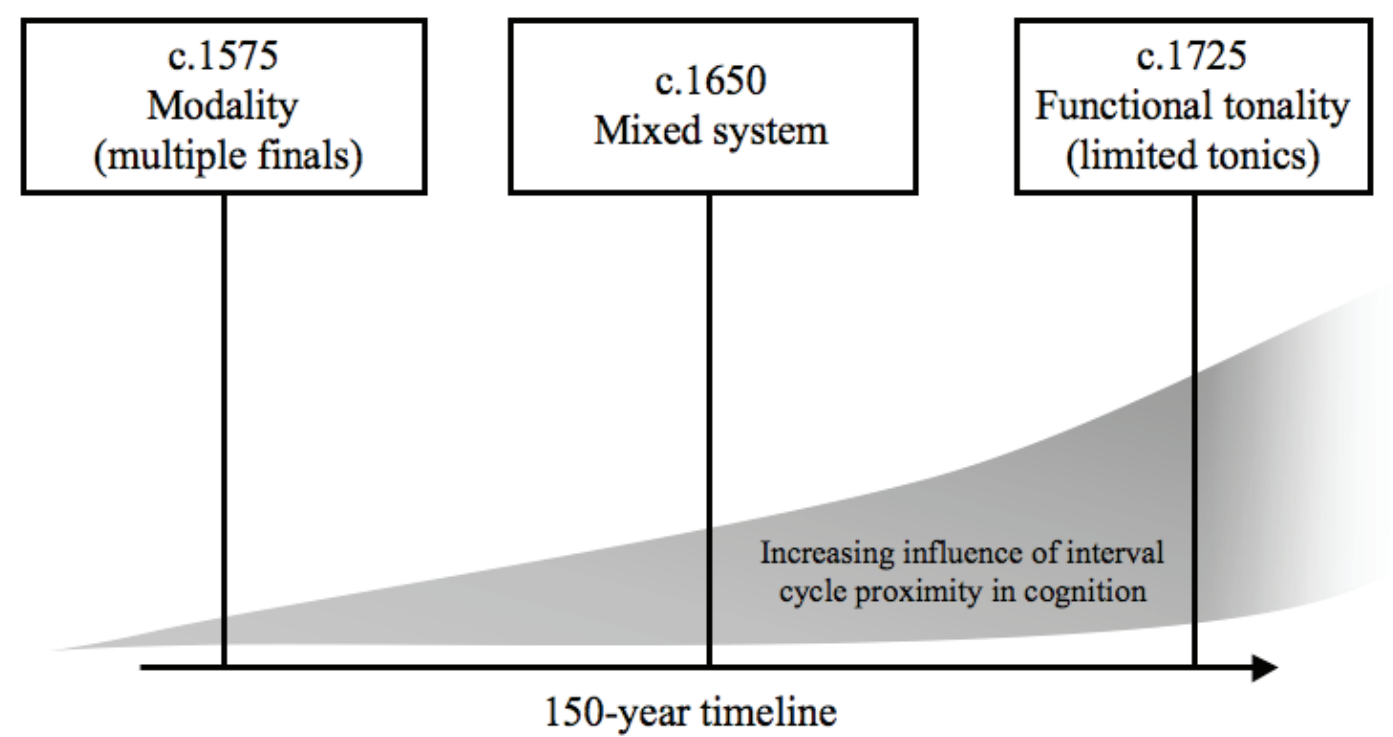

Fig. 8. Schematic diagram outlining the hypothesized role played by interval cycle proximity in the development of Western music from the sixteenth century to the early eighteenth century. The increasing influence of interval cycle proximity in cognition is represented by the increasing width of the grey band running from left to right in the figure.

To summarise, in the early sixteenth century ICP played little or no part in the cognition of tonal attraction, and as a consequence within the modal diatonic system a number of different finals were possible. In the seventeenth century, ICP became increasingly important cognitively, and as a result some pitches and triads (due to their interval configurations) acquired a greater degree of attraction than others. The greater sense of tonal attraction of certain pitches over others led to the establishment of fixed 'tonic' elements, principally those of major and minor tonality. In the seventeenth century some chord pair transitions became standardised due to their high level of attraction, a process that culminated with the maturation of functional tonality in the early eighteenth century.

\section{Summary Conclusion}

This article has applied a novel pitch grouping process - interval cycle proximity (ICP) - to the historical issue of the emergence of major-minor tonality. In Section 1, following a brief explanation of ICP and its associated hypothesis and model, Brower's perceptual binding model (Brower, 2000) was used to show how ICP might be linked to tonal attraction; that is, how interval cycles might be responsible for controlling the strength of 'pull' or 'magnetism' between temporally adjacent musical elements. In Section 2 evidence was presented that showed interval cycles to be consistent with music-theoretic accounts of tonal harmony. This included (1) demonstrating that the tonics of the diatonic and harmonic minor scales have higher aggregate interval cycle values than non-tonics; (2) presenting model-generated chord attraction profiles in which standard progressions, such as G-C, had the highest levels of attraction; and (3) analysing Piston's Table of Usual Root Progressions and Schmuckler's empirically related data in terms of tonal attraction. In each case the ICP hypothesis was found to be compatible with common practice period tonality. In Section 3 it was proposed that from the latter part of the sixteenth century the increasing influence of ICP in cognition led to some pitches becoming perceptually more important than others due to their high level of attraction, which in turn led the tonics to become 'fixed'.[21] In addition to outlining how ICP may have helped bring about the emergence of major-minor tonality, Section 3 also sought to illustrate a general perceptual principle: that the organisation of pitch in tonal-harmonic music is a by-product of an underlying cognitive process, subject to change depending on the degree of influence of the cognitive process at a given moment in history. ICP is hypothesised to be just such a process, influencing the level of tonal 
attraction between temporally adjacent musical elements in different ways depending on whether the music in question is from the sixteenth, seventeenth or eighteenth centuries.

Before concluding, a few words concerning the considerable limitations of this study are required. First, the chord attraction profiles presented in Figures 4 and 5 relied on two components of the model, Interval Cycles and Root Salience. While this parsimonious version of the model has the benefit of illustrating the possible power of interval cycles with respect to tonal attraction, the omission of other components means that important effects such as voice leading were not explored. Second, no textual analysis in the form of real music was offered to support the central proposition that ICP contributed to the establishment of major-minor tonality, and as a result the article relies on theoretical descriptions modal and tonal music. Real music from the seventeenth century (and earlier) may tell a different story from the one proposed in this article, and one far more complex than the pre- and post-ICP world that I have suggested exists. In order to explore the possible implications of the hypothesis presented here, additional methods of analysis are needed that are able to assess the hypothesised influence of ICP in music before 1600 , perhaps involving empirical and statistical research similar to that carried out by Huron and Veltman (2006).

As stated in the introduction to this article, the historical development of tonality is still virgin territory for cognitive musicologists. If this area of research is to be opened up for exploration, cognitive theories and research methods must be further developed that are capable of explaining some of the important changes in tonal organisation throughout the past 500 years.

\section{NOTES}

[1] Abbatini's poem is quoted in full in the English translation by David Bryant of Lorenzo Bianconi's Music in the Seventeenth Century, pp. 286-92.

[2] Two other pioneering studies are the work into melodic redundancy of Youngblood (1958), who calculated tone transition probabilities in the Liber Usualis, and Krumhansl's (1990) correlation analysis of her tonal hierarchy data using Youngblood's pitch distribution information, similar to the "mode profiles" of Huron and Veltman. For a critical appraisal of Huron and Veltman (2006), see Wiering (2006).

[3] The "tenor" is the reciting tone to which most of the text is sung.

[4] The Ionian and Aeolian modes can be considered the analogues of $\mathrm{C}$ major and A minor.

[5] For a more detailed description, see Woolhouse and Cross (2010).

[6] The Appendix contains a formal description of the model. For more detailed descriptions and supporting empirical research, see Woolhouse (2007) and Woolhouse (2009).

[7] The profile in Figure 3 correlates significantly with Krumhansl and Kessler's (1982) minor-key tonal hierarchy, a fact which is explored in detail in Woolhouse and Cross (2010).

[8] Brower's cognitive theory is based on the work of the social scientist Howard Margolis (1987) and the philosopher Mark Johnson (1987). An example of projecting bodily experiences onto patterns in other domains might be 'balance schemata', in which our acquired knowledge of physical balance enables us to understand ideas such as visual balance, emotional balance, and perhaps even concepts such as political bias.

[9] For an alternative and extensive account of embodied music cognition, see Leman (2007). In Leman's theory the body is seen as mediator between, on the one hand, physical sound and, on the other, the mental experience of music. This approach provides a framework within which to develop tools for integrating artistic expression with modern technology. 
[10] The 'common practice period' refers to European art music from ca 1600 to 1900, and encompasses the music of the Baroque, Classical and Romantic eras.

[11] Interval cycles are invariant with respect to transposition. For example, if the pitch classes in Table 2 were transposed up a perfect fifth to G major, the interval cycle of C-D (6) would simply be transferred to G-A (also 6).

[12] For the sake of simplicity, the variables controlling components Consonance \& Dissonance and Voice Leading were set to null values so that these components did not contribute to the model. As a result, only components Interval Cycles and Root Salience significantly contributed to the profile shown in Figure 4. For component Root Salience, $\beta=4, \gamma=8$; see Appendix.

[13] As in Figure 4, only model components Interval Cycles and Root Salience significantly contributed to the profile shown in Figure 5.

[14] The attraction level of G-bo (0.454), i.e., a sensory consonance to a sensory dissonance, would be lower had component Consonance \& Dissonance contributed to the model. i.e., had $\delta$, the variable controlling the influence of dissonance in the model, been greater than zero. The model deals with 'firstorder' transitions and consequently does not take into account the effect of harmonic non-adjacency. Despite this limitation, previous studies of sequential chord processing indicate that events immediately prior to the perceptual present are significantly more important than events sometime prior to the perceptual present (Tillmann \& Bigand, 1998). Although this does not necessarily indicate that local tonal attractions are unaffected by global structures, it does suggest that the experience of music's harmonic component may, to some extent, be modelled as a concatenation of discrete transitions.

[15] Although Piston did not explicitly state why these progressions were not included in his table, it is assumed that their exclusion was due to their infrequent occurrence.

[16] Spearman's rank correlation coefficient was used because Piston's chord transition categories are ordinal data.

[17] All translations are from Lester (1989, pp. 6, 43, 88, 98, 115).

[18] The term "tonic" was not introduced until 1710 by Saint Lambert in his treatise Nouveau traite de l'accompagnement (Lester, 1989, p. 100).

[19] The interval configuration of the minor key was, of course, frequently altered by raising the leading tone.

[20] Krumhansl (1990, p. 19) states: "[Pitch stability] is taken to refer to the dimension along which musical tones differ, with some tones producing an unstable effect requiring resolution, and other tones producing a stable effect and giving a sense of completion."

[21] For a deconstructionist approach to the development of tonal music within Europe, see the Marxist feminist work of Susan McClary. For example, in her book Feminine Endings (1991), McClary proposes that Sonata Form can be viewed as gendered discourse in which a "feminine" second subject is systematically explored within the controlling ambit of a dominating and even imperialistic "masculine" first subject. This approach holds that music symbolises or is a metaphor for the prevailing socio-political themes and tropes of a particular time in history.

\section{REFERENCES}

Abbatini, A. M. (c. 1667). Letter to Sig. Bastiano Baldini, Biblioteca Vaticana, Rome, MS Chigi L. VI.191. 
Allen, D. (1967). Octave discriminability of musical and nonmusical subjects. Psychonomic Science, Vol. 7, pp. 421-22.

Barnett, G. (2002). Tonal organization in seventeenth-century music theory. Cambridge History of Western Music Theory, ed. Thomas Christensen, Cambridge University Press, pp. 407-455.

Bharucha, J. J. (1996). Melodic anchoring. Music Perception, Vol. 13, No. 3, pp. 383-400.

Bianconi, L. (1982). Il Seicento, Turin, Edizioni di Torino; trans. D. Bryant (1987) as Music in the Seventeenth Century, Cambridge University Press.

Brower, C. (2000). A cognitive theory of musical meaning. Journal of Music Theory, Vol. 44, No. 2, pp. 323-379.

Chafe, E. T. (1992). Monteverdi's Tonal Language. New York: Schirmer Books.

Dahlhaus, C. (1990). Studies on the Origin of Harmonic Tonality. (R. O. Gjerdingen, trans.) Princeton: Princeton University Press.

Deliège, I., Mélen, M., Stammers, D., \& Cross, I. (1996). Musical schemata in real time listening to a piece of music. Music Perception, Vol. 14, No. 2, pp. 117-160.

Demany, L. \& Armand, F. (1984). The perceptual reality of one chroma in early infancy. Journal of the Acoustical Society of America, Vol. 76, pp. 57-66.

Dowling, W. J. \& Harwood, D. L. (1986). Music Cognition. Orlando, FL: Academic.

Glarean, H. (1547). Dodecachordon. Basel, H. Petri; facs. Hildesheim, G. Olms, (1969), and New York, Broude, (1967); trans. C. Miller, MSD 6 (1965).

Huron, D. \& Veltman, J. (2006). A cognitive approach to medieval mode: Evidence for an historical antecedent to the major/minor system. Empirical Musicology Review, Vol. 1, No. 1, pp. 33-55.

Johnson, M. (1987). The body in the mind: The bodily basis of meaning, imagination, and reason. Chicago: University of Chicago Press.

Krumhansl, C. L. (1990). Cognitive foundations of musical pitch. Oxford: Oxford University Press.

Krumhansl, C. L. \& Kessler, E. J. (1982). Tracing the dynamic changes in perceived tonal organization in a spatial representation of musical keys. Psychological Review, Vol. 89, pp. 334-68.

Larson, S. (2004). Musical Forces and Melodic Expectations: Comparing Computer Models with Experimental Results. Music Perception. Vol. 21, No, 4, pp. 457-498.

Leman, M. (2007). Embodied Music Cognition and Mediation Technology. Cambridge, MA: MIT Press.

Lester, J. (1989). Between Modes and Keys: German Theory 1592-1802. New York: Stuyvesant.

Lippius, J. (1612). Synopsis musicae novae. Strasbourg. English translation by B. V. Rivera (1977). Colorado Springs: Colorado College Music Press.

Lockhead, G. R. \& Byrd, R. (1981). Practically perfect pitch. Journal of the Acoustical Society of America, Vol. 70, pp. 387-89. 
Margolis, H. (1987). Patterns, thinking, and cognition: A theory of judgment. Chicago: University of Chicago Press.

Mattheson, J. (1713). Das neu-eröffnete Orchestre. Hamburg, B. Schiller; facs. Hildesheim, G. Olms, (1997).

McClary, S. (1991). Feminine Endings: Music, Gender, and Sexuality. Minneapolis, MN: University of Minnesota Press.

McClary, S. (1994). Constructions of Subjectivity in Schubert's Music. In Queering the Pitch: The New Gay and Lesbian Musicology, ed. Philip Brett, Elizabeth Wood, and Gary C. Thomas, New York: Routledge, pp. 205-233.

Meyer, L. (1956). Emotion and meaning in music. Chicago, University of Chicago Press.

Ozanam, J. (1691). Dictionaire mathématique. Amsterdam.

Parncutt, R. (1989). Harmony: a psychoacoustical approach. Berlin: Springer-Verlag.

Piston, W. (1978). Harmony. 4th edition; New York: Norton. (Originally published, 1941.)

Powers, H. S. / Wiering, F. (2001). Mode: II. Medieval modal theory. Stanley Sadie (Ed.). The New Grove Dictionary of Music and Musicians, $2^{\text {nd }}$ ed. New York: Grove.

Saint Lambert. (1710). Nouveau traite de l'accompagnement. Amsterdam.

Schmuckler, M. A. (1989). Expectation in music - investigation of melodic and harmonic processes. Music Perception, Vol. 7, No. 2, pp. 109-150.

Terhardt, E. (1984). The concept of musical consonance: a link between music and psychoacoustics. Music Perception, Vol. 1, pp. 276-95.

Thurlow, W. R. \& Erchul, W. P. (1977). Judged similarity in pitch of octave multiples. Perception \& Psychophysics, Vol. 22, pp. 177-82.

Tillmann, B. \& Bigand, E. (1998). Influence of global structure on musical target detection and recognition. International Journal of Psychology, Vol. 33, No. 2, pp. 107-122.

Werkmeister (1687), Musicae mathematicae. Frankfurt and Leipzig.

Wiering, F. (2006). Comment on Huron and Veltman: Does a cognitive approach to medieval mode make sense? Empirical Musicology Review, Vol. 1, No. 1, pp. 56-60.

Wiering, F. (2001). The Language of the Modes. Studies in the History of Polyphonic Modality (Criticism and Analysis of Early Music, 3). New York, U.S.A. \& London, England: Routledge.

Woolhouse, M. H. (2007). Interval cycles and the cognition of pitch attraction in Western tonal-harmonic music. Unpublished doctoral thesis, University of Cambridge, UK.

Woolhouse, M. H. (2009) Modelling tonal attraction between adjacent musical elements. Journal of New Music Research, Vol. 38, No. 4, pp. 357-379.

Woolhouse, M. H. \& Cross, I. (2010). Using interval cycles to model Krumhansl's tonal hierarchies. Music Theory Spectrum. Vol. 32, No. 1, pp. 62-78. 
Wright, A.A., Rivera, J.J., Hulse, S.H., Shyan, M., Neiworth, J.J. (2000). Music perception and octave generalization in rhesus monkeys. Journal of Experimental Psychology: General, Vol. 129, pp. 291-307.

Youngblood, J. E. (1956). Style as information. Journal of Music Theory, Vol. 2, pp. 24-35.

\section{APPENDIX}

\section{ICP Model}

Within the model, component Interval Cycles is the most important in terms of the extent to which it contributes to the calculation of tonal attraction. However, in addition to Interval Cycles, there are a number of other components that are designed to modify the calculation of tonal attraction depending on the type of music being modelled. For example, if the attraction between functionally unambiguous diatonic chords is being modelled, i.e., between chords with identifiable roots, component Root Salience (a weighting method applied to the chords' root relationships) influences the calculation significantly. Alternatively, if the attraction between functionally ambiguous chromatic chords is being modelled, i.e., between chords with ill-defined roots, Root Salience does not influence the calculation.

\section{MUSIC}

Given two successive chords (a chord is defined as a simultaneity containing one or more notes): past chord, $\mathrm{X}$, and present chord, $\mathrm{Y}$

$\mathrm{X}=\left\{\mathrm{x}_{1}, \mathrm{x}_{2}, \ldots, \mathrm{x}|\mathrm{X}|\right\} \quad \mathrm{x}_{1}<\mathrm{x}_{2}<\ldots<\mathrm{x}|\mathrm{X}|$

$\mathrm{Y}=\left\{\mathrm{y}_{1}, \mathrm{y}_{2}, \ldots, \mathrm{y}|\mathrm{Y}|\right\} \quad \mathrm{y}_{1}<\mathrm{y}_{2}<\ldots<\mathrm{y}|\mathrm{Y}|$

where $|X|=$ size of set $X,|Y|=$ size of set $Y$, and where $x_{i}$ and $y_{j}$ are defined with reference to $C_{4}=60$.

Component Music defines the number of pitches in the past chord (X) and the present chord $(\mathrm{Y})$ and assigns each an integer value relative to $\mathrm{C}_{4}$.

\section{PITCH DISTANCE}

Form matrix PD where

$$
\mathrm{PD}_{\mathrm{ij}}=\left|\mathrm{y}_{\mathrm{j}}-\mathrm{x}_{\mathrm{i}}\right| \quad \begin{aligned}
& \mathrm{i}=1,2, \ldots,|\mathrm{X}| \\
& \mathrm{j}=1,2, \ldots,|\mathrm{Y}|
\end{aligned}
$$

$\mathrm{PD}$ (pitch distance) is a pitch distance matrix measured in semitones.

\section{INTERVAL CYCLES}

Form matrix IC where

$$
\begin{aligned}
\mathrm{IC}_{\mathrm{ij}} & =\frac{12}{h c f\left(\mathrm{PD}_{\mathrm{ij}}, 12\right)} \text { for } \mathrm{PD}_{\mathrm{ij}}{ }^{1} 0 \\
\mathrm{IC}_{\mathrm{ij}} & =1 \text { if } \mathrm{PD}_{\mathrm{ij}}=0
\end{aligned}
$$

where $h c f(\mathrm{a}, \mathrm{b})$ is the highest common factor of $\mathrm{a}$ and $\mathrm{b}$, and $\mathrm{a}, \mathrm{b}$ are whole numbers.

Distance values from matrix PD are converted into interval cycles in matrix IC (interval cycles). 


\section{VOICE LEADING}

Define a further matrix VL such that

$$
\mathrm{VL}_{\mathrm{ij}}=\frac{\alpha}{\mathrm{PD}_{\mathrm{ij}}+\alpha} \text { for some } \alpha>0
$$

Component Voice Leading controls the influence of pitch distance, i.e., semitone distance, using operand $\alpha$. The rational underpinning this component is that if the semitone distance between two pitches is small, the level of tonal attraction will increase, and visa versa. If no influence of pitch distance is required in the model, the value of operand $\alpha$ is set to infinity.

\section{INTERVAL CYCLES \& VOICE LEADING}

Using entry-wise multiplication (array multiplication), combine matrix VL with matrix IC to give matrix ICVL, defined by

$\mathrm{ICVL}_{\mathrm{ij}}=\mathrm{VL}_{\mathrm{ij}} \mathrm{IC}_{\mathrm{ij}}$

This component allows the influence of the semitone distance to be combined with interval cycles to produce a single value per matrix entry.

\section{ROOT SALIENCE}

Form matrix RS1 where

$$
\begin{array}{ll}
\mathrm{RS} 1_{\mathrm{ij}}=1 & \mathrm{i}=1,2, \ldots,|\mathrm{X}| \\
\mathrm{j}=1,2, \ldots,|\mathrm{Y}|
\end{array}
$$

If either chord has an identifiable root, let the row corresponding to the past root be the $\mathrm{m}^{\text {th }}$ row and the column corresponding to the present root be the $\mathrm{n}^{\text {th }}$ column.

Form matrix RS2 where

$$
R S 2_{i j}=\left\{\begin{array}{l}
R S 1_{i j} \text { if } i \neq m \\
R S 1_{i j} \text { if } j \neq n \\
\beta \times R S 1_{i j} \text { if } i=m \text { for some } \beta>1 \\
\gamma \times R S 1_{i j} \text { if } j=n \text { for some } \gamma>\beta
\end{array}\right.
$$

such that root intersection entry $\mathrm{RS} 2_{\mathrm{mn}}=\beta \times \gamma \times \mathrm{RS} 1_{\mathrm{mn}}$. If neither chord has an identifiable root, form matrix RS2 where

$R S 2_{i j}=R S 1_{i j}$

Form matrix RS3 where

$$
R S 3_{i j}=\frac{R S 2_{i j}}{\sum_{i=1}^{|X|} \sum_{j=1}^{|Y|} R S 2_{i j}}
$$

Component Root Salience is based on the idea that root relationships in functional tonal music are of greater perceptual importance, and must therefore be weighted more strongly than non-root relationships. The perception of tonal attraction depends strongly on music's temporal nature; that is, music is comprised of events in the perceptual past moving to events in the perceptual present. Studies into the nature of 
memory have found that the perception of an event is subject to temporal decay or interference, and therefore that events in the present are perceptually privileged with respect to those in the past. This notion is modeled by stating that if both chords have roots, the root of the present chord ( $\mathrm{n}$ of $\mathrm{Y}$ ) must be weighted more strongly than the root of the past chord ( $\mathrm{m}$ of $\mathrm{X}$ ).

\section{CONSONANCE \& DISSONANCE}

(i) If chords $\mathrm{X}$ and $\mathrm{Y}$ are both sensory consonances, or both are sensory dissonances, form matrix $\mathrm{CD}$ where

$\mathrm{CD}_{\mathrm{ij}}=\mathrm{RS}_{\mathrm{ij}}$

(ii) If chord $\mathrm{X}$ (past) is dissonant and chord $\mathrm{Y}$ (present) is consonant, form matrix CD where

$\mathrm{CD}_{\mathrm{ij}}=(1+\delta) \times \mathrm{RS}_{\mathrm{ij}}$ for some $\delta>0$

(iii) If chord $\mathrm{X}$ (past) is consonant and chord $\mathrm{Y}$ (present) is dissonant, form matrix $\mathrm{CD}$ where

$\mathrm{CD}_{\mathrm{ij}}=(1-\delta) \times \mathrm{RS}_{\mathrm{ij}}$ for some $\delta>0$

The effect of consonance and dissonance on tonal attraction is assumed to depend on temporal order. If the past chord $(\mathrm{X})$ is dissonant and the present chord $(\mathrm{Y})$ is consonant, then component Consonance \& Dissonance increases the level of tonal attraction, and visa versa.

\section{TONAL ATTRACTION}

Using entry-wise multiplication (array multiplication), combine matrix ICVL with matrix CD to give matrix TA, defined by

$\mathrm{TA}_{\mathrm{ij}}=\mathrm{ICVL}_{\mathrm{ij}} \mathrm{CD}_{\mathrm{ij}}$

Sum the entries in matrix TA to produce the overall attraction value, A, where

$\mathrm{A}=\frac{\sum_{\mathrm{i}=1}^{|\mathrm{X}|} \sum_{\mathrm{j}=1}^{|\mathrm{Y}|} \mathrm{TA} \mathrm{A}_{\mathrm{ij}}}{12}$

Using entry-wise multiplication (otherwise referred to as "array multiplication"), matrix TA (tonal attraction) combines interval cycle and voice leading information from matrix ICVL with root salience and consonance and dissonance information from matrix CD. Lastly, the entries of matrix TA are summed and scaled $(\mathrm{x} / 12)$ to produce a single tonal attraction value, $\mathrm{A}$. 